\title{
THE LARVAE OF THE GENUS PORCELLANA (CRUSTACEA DECAPODA) AND RELATED FORMS
}

\author{
By Marie V. Lebour, D.Sc. \\ Naturalist at the Plymouth Laboratory
}

(Text-figs. I-I2)

Although the larva of Porcellana is one of the earliest known decapod larvae and at a later date the different stages of $P$. longicornis were well described by Sars (1889), there is yet much that is unknown. Few larvae have been actually hatched from the egg and in no case has the number of larval stages been definitely ascertained. In order to fill in some of the gaps in our knowledge a detailed study of the two common Plymouth species was begun ( $P$. longicornis and $P$. platycheles). Unfortunately, war conditions made it difficult to obtain material and many specimens were lost as the result of air-raids; it was therefore not until the summer of 1942 that the work could be finished.

It is now possible to distinguish between the two species in all stages. Both have been hatched from the egg, larvae from the plankton have moulted and the post-larvae have been obtained from the last larvae. A comparison with Gurney's (1938a) notes on the species from the Red Sea and his general comments on the larvae of the genus and its relatives (1942) is of much use. These, with the first larvae of Petrolisthes armatus hatched by myself at Bermuda and certain larvae described by other workers, have made it possible to make some progress in the elucidation of the relationships of the larvae.

Porcellana longicornis and $P$. platycheles are both common at Plymouth; but whereas the latter is confined to coastal waters and lives between tidemarks and down to about 3 fathoms, the former has a much wider range and although occurring with $P$. platycheles between tidemarks extends to well beyond the Eddystone grounds. It was thought that a third species was present in the outside waters (see Gurney, I942), but this larva has now been proved to belong to $P$. platycheles.

Large numbers of Porcellana larvae are caught in the tow-nets from between the Breakwater and the Rame-Eddystone grounds. It has always been assumed that these represented the two species. All the late larvae, with the exception of a very few specimens, rarely obtained, possessed three pairs of pleopods and this fact gave rise to the assumption that both species had only three pairs. The few specimens with four pairs of pleopods were regarded as a new species. It is now certain that all those with three pairs of pleopods 
belong to $P$. longicornis and the few rare specimens with four pairs belong to $P$. platycheles. The fact that under present conditions tow-nettings were unobtainable beyond the Breakwater led to the detailed study of the plankton of the inshore waters-hitherto rather neglected for the richer outside hauls. Larvae of $P$. platycheles (recognized from comparison with those hatched from the parent) were collected in these hauls and moults from the first to the second stages obtained, proving without a doubt that $P$. platycheles has four pairs of pleopods and is identical with the form rarely present in the outside hauls. The larvae of $P$. platycheles, however, are never plentiful even in the inshore samples, probably because of their large size and because only small tow-nets can at present be used. Larvae of $P$. longicornis are more abundant, but they are not caught in large numbers. It is samples taken with the $2 \mathrm{~m}$. ring trawl at Station $\mathrm{L}_{4}$ and beyond, which at times are so full of the larvae of $P$. longicornis.

$P$. longicornis breeds from January to November, the larvae being most abundant in spring and summer. $P$. platycheles has a shorter breeding season beginning in April or May (very rarely March) and finishing by September, June to the end of July being its usual maximum breeding period.

Sars (1889) has described the larvae of $P$. longicornis in detail; he found two distinct stages in the plankton, but suggested that the earliest was not the first-a suggestion which is supported by hatching the larvae at Plymouth. A later stage than his last also occurs at Plymouth although the post-larvae obtained all moulted from the less developed form similar to his last. His description of the two stages of $P$. longicornis may be taken as typical of the two main stages of a Porcellanid larva. As is shown below, however, there are three or four stages (possibly five) in $P$. longicornis and two (possibly three) in $P$. platycheles.

In all Porcellanid larvae known there are two main stages (I and II). Stage I is exemplified by Sars's earliest stage, in which the exopods of the first and second maxillipedes bear 4 setae and the telson $7+7$ setae, the third maxillipede and legs being rudimentary and very small. Stage II is exemplified by Sars's last stage, in which the exopods of the first and second maxillipedes bear IO-I2 setae, that of the third either having setae (usually 4) or not, the endopod and also the legs being non-functional, but more developed. The telson either has $8+8$ setae (Porcellana) or $7+7$ with a central tooth (Petrolisthes). The first of the main stages may include two, called here I $a$ and $\mathrm{I} b$, and the second may include two or three, called here II $a$, II $b$ and II c. Gurney (1938a) found only two stages in Porcellana inaequalis and Petrolisthes? sp. from the Red Sea. Menon (1937) concluded that there were probably three in his Indian Porcellanids.

The young is hatched as a pre-zoea (Fig. I $a$ ) which is much the same in all the species in which it is known. It lives for some hours, coming up to 
the light and to the surface and swimming vigorously. The antennule has two large feathered apical spines with aesthetes showing at the base, and may or may not have a lateral spine (Fig. I $b$ ). The antenna (Fig. I $c$ ) has 5 large spines covering the zoeal exopod and a single spine over the endopod (Porcellana longicornis, $P$. platycheles and $P$. inaequalis) or 6 over the exopod in
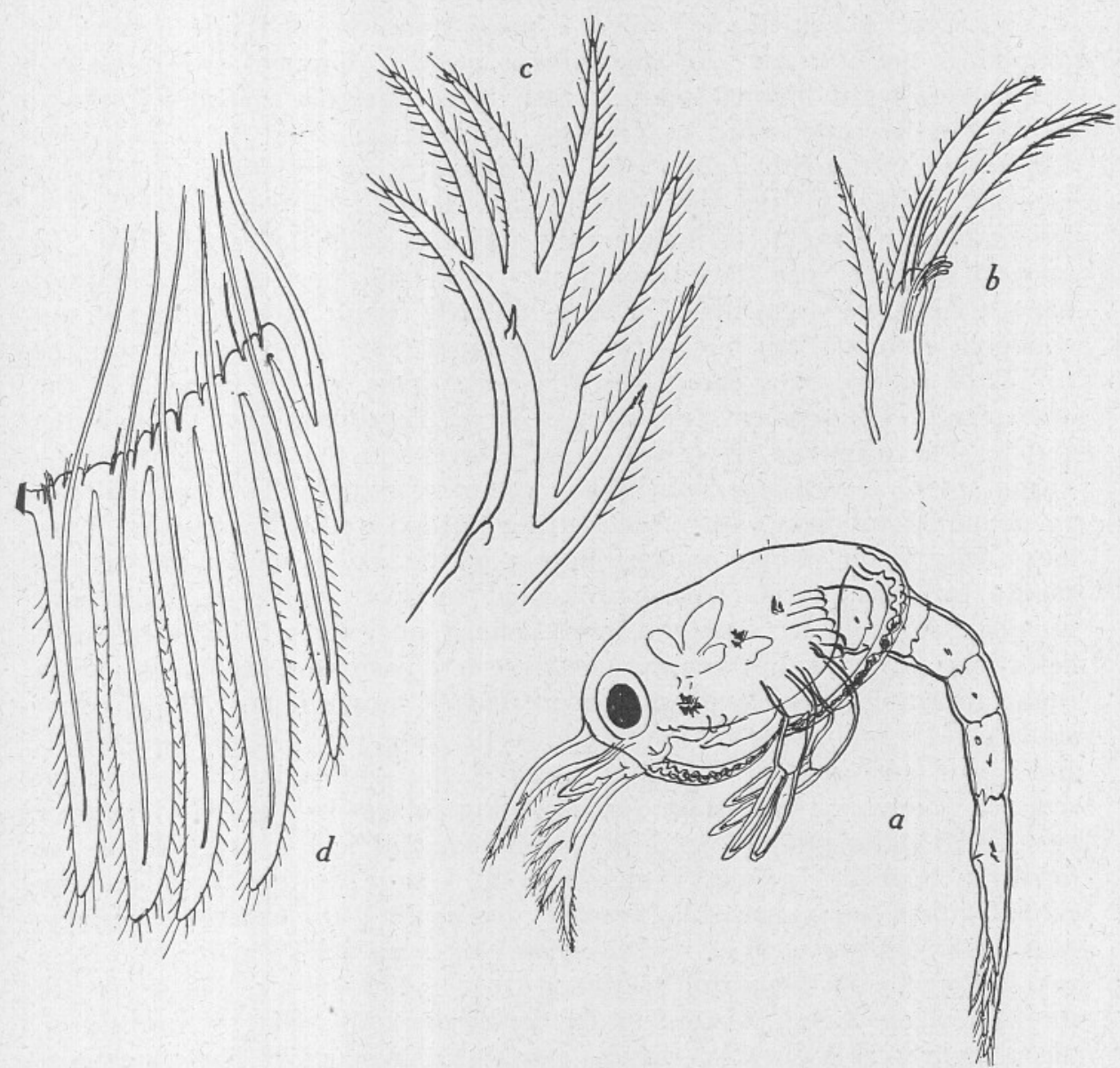

Fig. I. Pre-zoea of Porcellana platycheles: $a$, side view, $2 \cdot 4 \mathrm{~mm}$. long without long spines; $b$, antennule; $c$, antenna; $d$, telson.

a species from Samoa described by Gurney (1926, 1942) in which there is also a lateral spine on the endopod. The telson has $6+6$ spines, the first small and smooth, the others long and feathered. There is no trace of the second zoeal spine until just before the pre-zoeal cuticle is shed, when it may be present as a minute rudiment. The small posterior spine of the zoea internal to the seventh spine is included in the sixth pre-zoeal spine (Fig. I $d$; 
see also Gurney, 1942, p. 53, fig. I4a). The rostral and posterior carapace spines of stage I are crumpled up under the pre-zoeal cuticle.

The pre-zoea moults into stage I, either $a$ or $b$ ( $a$ in $P$. longicornis, $b$ in $P$. platycheles). The zoea in all stages has a very long rostral spine and the posterior angles of the carapace are drawn out into long spines, the posterior carapace spines. The telson is triangular and bluntly pointed posteriorly. The second spine is hair-like. There is a small spine on each side posteriorly internal to the fifth seta. An anal spine is present. Uropods are absent and there are only 5 abdominal somites which may or may not have lateral spines. [A curious larva described by Gurney (1924c, 1942) from the Terra Nova Expedition and possibly not a true Porcellanid, is exceptional in possessing uropods in stage II, the telson deeply forked and an antennal scale.] The antennule is a simple rod armed with aesthetes and setae at the tips. In stage II segments may show through the cuticle and there may be groups of hairs to mark the segments. The antenna has a simple rod-like exopod and endopod without setae, but usually there are a few minute spines near the tip of the endopod and sometimes a hair-like spine on the exopod. In the latest stages the segments of the post-larval flagellum show through the cuticle. The mandible is without a palp (except in the form identified by Faxon (1879) as Polyonyx, which has a rudimentary one). The maxillule has an unjointed endopod with 3 setae at the tip and well-defined setose inner lobes. The outer margin bulges slightly in the region where the exopod should be. The maxilla has an unjointed endopod with 3 terminal and, usually, 2 pairs of inner setae and 4 well-defined inner setose lobes; the exopod has a long posterior lobe bearing one large seta posteriorly and 5 or 6 setae round the anterior and outer margin in stage I, more in stage II. The first and second maxillipedes are functional with 4 setae on the exopod in stage I, and IO-I2 setae in stage II, and an endopod of 4 segments with no external setae on segments $\mathrm{I}-3$ in stage I, these being present in stage II. There are very small rudiments of the third maxillipede and legs in stage $I$, but the former is bilobed. In stage II the endopod is large, but not functional, the exopod either being unarmed (Porcellana inaequalis, Petrolisthes sp. (Gurney, I939a)) or bearing setae (4 in Porcellana longicornis and P. platycheles, 3, 4 or 6 in Porcellanids described by Menon (1937)). The legs are non-functional, the fifth being curved forward under the others and chelate. There are no pleopods in stage I, but there may be 3 or 4 pairs in stage II. These are never setose, but are long in the stage (II $b$ or II $c$ ) which changes to the post-larva. The post-larva differs markedly from the adult and certain characters have not yet appeared. There are now six abdominal somites and setose uropods; 3 or 4 pairs of setose pleopods are present. The telson is a plain plate. The legs are functional and the antennal flagellum long.

The number of larval stages varies in different species and even in the same species, but stages I and II are always present." Stage I may consist of two stages (I $a, \mathrm{I} b)$ or of one stage only (I $b)$, stage II may consist of three 
stages (II $a, \mathrm{II} b, \mathrm{II} c$ ) or two (II $b, \mathrm{II} c$ ) or of one only (II $b$ ). It is impossible to be certain that there is a moult between $\mathrm{I} a$ and $\mathrm{I} b$ or between $\mathrm{II} b$ and II $c$ and a very wide range of individual variation is indicated. It is probable that the normal life-history of the genus is I $b$-II $b$-post-larva, as in P. platycheles (II $c$ also being present as an alternative to $\mathrm{II} b$ ) and possibly others, and these are more or less stable, but in P. longicornis (I $a$ or $b-\mathrm{II} a-\mathrm{II} b$ or $c-$ post-larva) there exists a state of great variability not as yet settled down to normal.
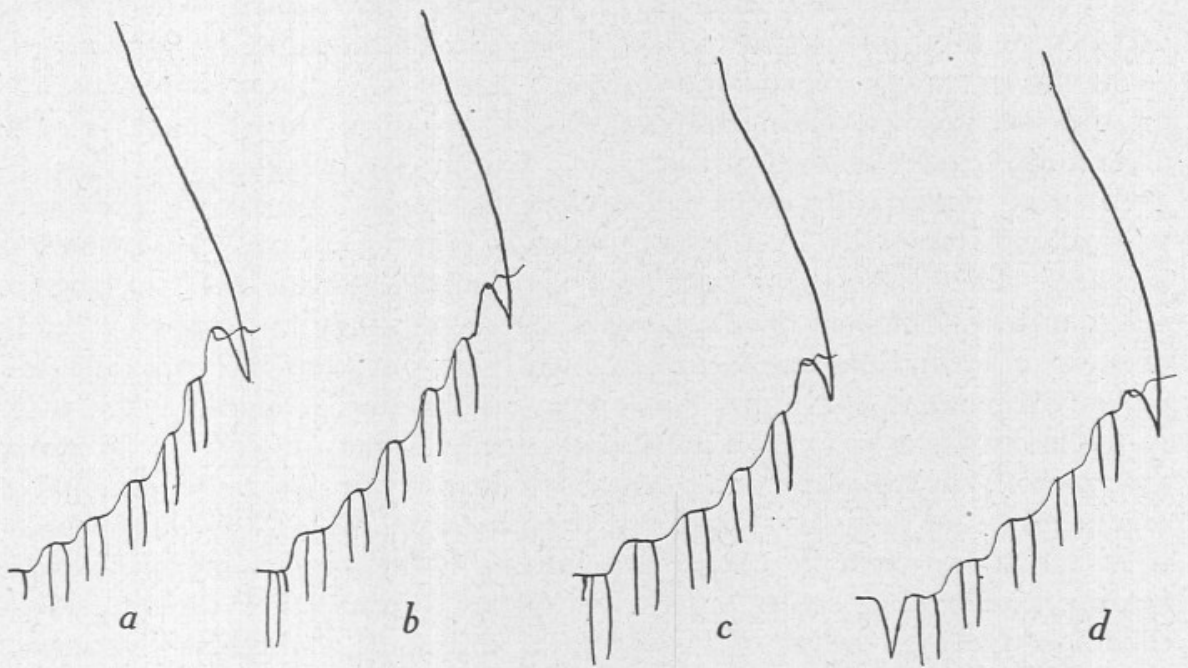

Fig. 2. Diagram of telson of Porcellana and Petrolisthes: a, Porcellana longicornis, stage I; $b, P$. longicornis, stage II; c, Petrolisthes armatus, stage I; d, Petrolisthes sp. (after Gurney), stage II.

Gurney (I938a) has shown that there are 4 pairs of pleopods in the larvae of Porcellana inaequalis and in Petrolisthes sp., and it is now found that there are also 4 pairs in Porcellana platycheles; therefore, as he truly remarks, this is not a generic character as there are 3 pairs in $P$. longicornis. $\mathrm{He}$ has also shown that Porcellana and Petrolisthes have a different type of telson respectively. Porcellana in stage I has the fifth long seta situated outside the central prominence, Petrolisthes has it on the central prominence (Fig. 2). In stage II Porcellana has a sixth long seta on the central prominence, whereas in Petrolisthes there is no sixth seta but a central tooth. As Petrolisthes armatus from Bermuda, moulted from the pre-zoea hatched from the egg, has a similar type of telson to Gurney's Petrolisthes it may safely be assumed that he is right in attributing his form to that genus. The type of telson thus appears to be a good generic character.

References to the early descriptions of unidentified Porcellanid larvae are here omitted, but Hesse (I884) has described the larva of what he regarded 
as Porcellana platycheles from the stomach of a mackerel. It appears from his description and figures that this is clearly $P$. longicornis.

\section{The LaRvae of the Genus PorCellana}

Of this genus we know the pre-zoea, stage I and stage II and post-larva of Porcellana longicornis (see Sars (I889) and the present work), P. platycheles (the present work) and $P$. inaequalis (pre-zoea and larvae only) from the Red Sea (see Gurney, 1938a). Menon (1937, I940) describes what he believes to be the larva and post-larva of $P$. serratifrons from India. Other larvae ascribed by him provisionally to Petrolisthes probably belong to Porcellana.

All the larvae are transparent with red, orange or yellow pigment, usually on the rostrum, posterior carapace spines, region of the stomach, on the abdominal somites and telson and at the base of the maxillipedes. The prezoea swims actively for some hours. The larvae are very active and swim vertically, horizontally or sideways, usually front foremost, dorsal surface upwards. They swim up to the light and usually remain near the surface when healthy. The main food consists of debris, but they are capable of eating dead or moribund organisms and frequently devour their own brothers and sisters. Sometimes the empty long spines can be seen emerging at the anus. A specimen was seen to eat a moribund copepod. The contents of the gut in specimens from the plankton are entirely detritus with no visible remains of organisms. The post-larva feeds on detritus also, picking up small pieces from the stones with its chelae and putting them into its mouth, besides feeding by the filter on its third maxillipedes as is usual in the adult Porcellanids. The post-larvae of $P$. longicornis and of $P$. platycheles which were watched used the third maxillipedes alternately as described by Nicol (1932) or both together. The fifth legs were used to pick off any extraneous substance from the body which was kept scrupulously clean.

All the known larvae of Porcellana agree in having the telson with the fifth long seta outside the central prominence in stage I, and in stage II having a sixth seta situated on the central prominence. The third maxillipede in stage II may bear 4 setae on its exopod ( $P$. longicornis, $P$. platycheles) or be unarmed $(P$. inaequalis, see Gurney, I938a). According to Menon (1937, 1940) there are 6 setae in the larva attributed to $P$. serratifrons.

\section{Porcellana longicornis (L.) (Figs. 3, 5-7, 8a, $b, 9$ )}

The earliest recorded female in berry occurred at the end of January (28. i. 38 ) in a Chaetopterus tube from the outside grounds. The eggs were nearly ready to hatch. The earliest larvae recorded in the plankton were at the end of February (24. ii. 38). In subsequent years they were later and they usually begin about March with a maximum from May to August and continue until October, rarely November. Early larvae were still in the inshore plankton in the middle of November I94I. The eggs when ready to hatch measure $0.48 \times 0.40 \mathrm{~mm}$. The pre-zoea is about $\mathrm{I} .6 \mathrm{~mm}$. in length, 
exclusive of the long spines on the antennae and telson. After swimming about for some hours at the surface nearest the light the pre-zoea moulted to the first larval stage, I $a$.

Stage Ia (Fig. $3 a, b$ ). This stage is distinctly smaller than Sars's first stage, the legs are not so well developed, but the posterior carapace spines are slightly longer. The newly moulted larva measures $4.5-4 \cdot 8 \mathrm{~mm}$. from spine to spine. Rostrum $2.9 \mathrm{~mm}$., posterior carapace spines I.I mm., or rather more, body $\mathrm{I} .6 \mathrm{~mm}$. in length. Red pigment occurs on the rostrum, chiefly at the tip and in the centre so as to form bars, in the mouth region, on the sides of the abdominal somites, on the base of the first and second maxillipedes and on the tips of the posterior carapace spines. The region of the liver is usually greenish. There are fine spines on the rostrum; the posterior spines each have two conspicuous spines ventrally near the origin, the first the

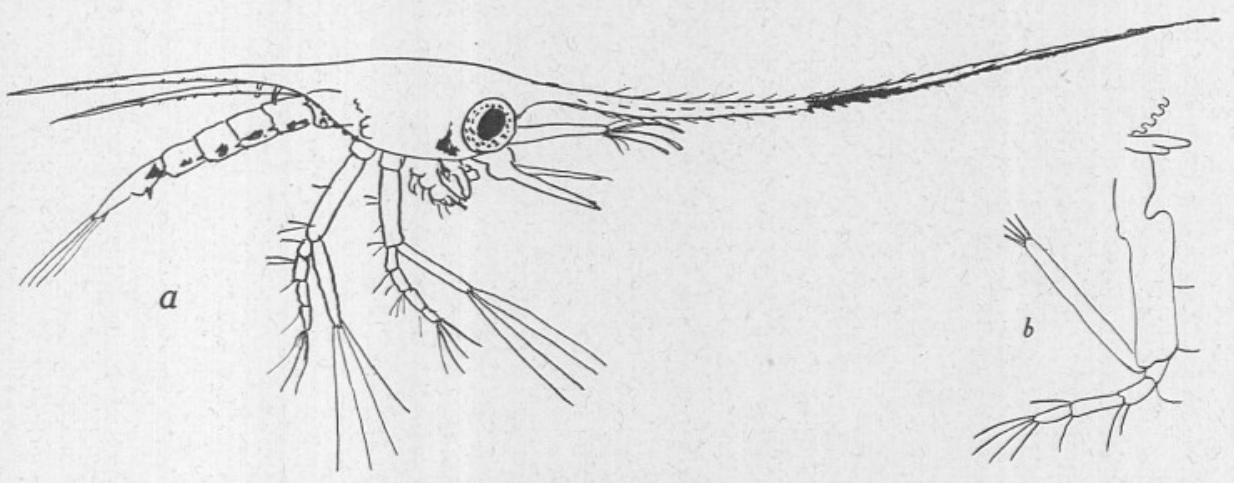

Fig. 3. Porcellana longicornis: $a$, stage I $a$ from pre-zoea from egg, $4.6 \mathrm{~mm}$. from spine to spine; $b$, second and third maxillipede and legs of same.

larger of the two, and small spines behind. This is an important difference in distinguishing the species from Porcellana platycheles, for in stage I of the latter the large spines are absent. The rudiments of the third maxillipedes are bilobed, but the legs are mere buds (Fig. $3 b$ ). The third seta of the telson (=the first long seta) is armed at the tip in a peculiar manner with large and conspicuous hook-like spines (Fig. 4a). The significance of these spines as a specific character was suggested by Dr Gurney (private communication) and is of importance, as here again we have a distinguishing character from $P$. platycheles in which the armature of the seta is quite different with long fine spines. Petrolisthes armatus has long fine spines at the ends of all the setae.

The pre-zoea in my experience has always moulted to $\mathrm{I} a$ and never to $\mathrm{I} b$. $\mathrm{I} a$ has once moulted to II $a$ which in all other cases came from I $b$. Thus $a$ and $b$ may be alternative stages. No moult has been observed from I $a$ to $\mathrm{I} b$ and the way in which $\mathrm{I} b$ arises is consequently uncertain. The specimen of II $a$ derived from I $a$ was smaller than those from $\mathrm{I} b$ and this may account for the great variation in size in the later stages. 

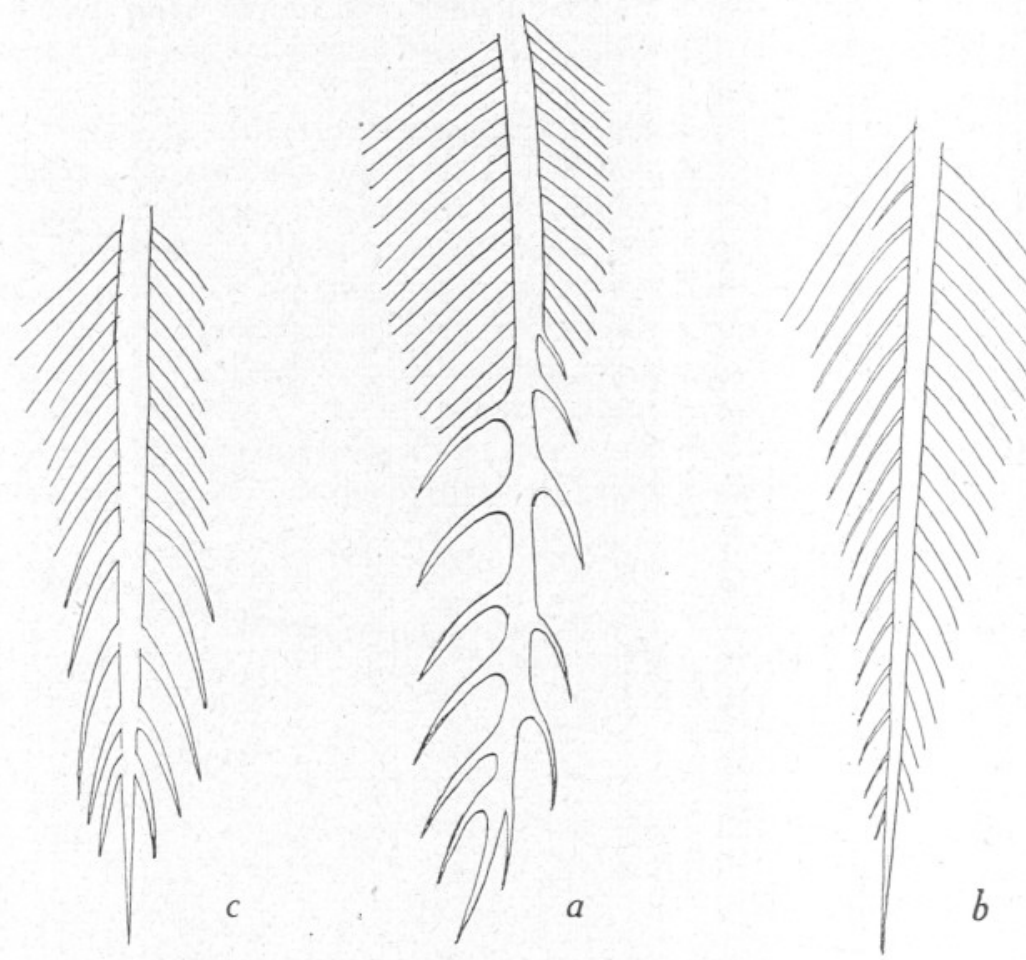

Fig. 4. Third seta of telson: $a$, Porcellana longicornis; $b, P$. platycheles; c, Petrolisthes armatus.

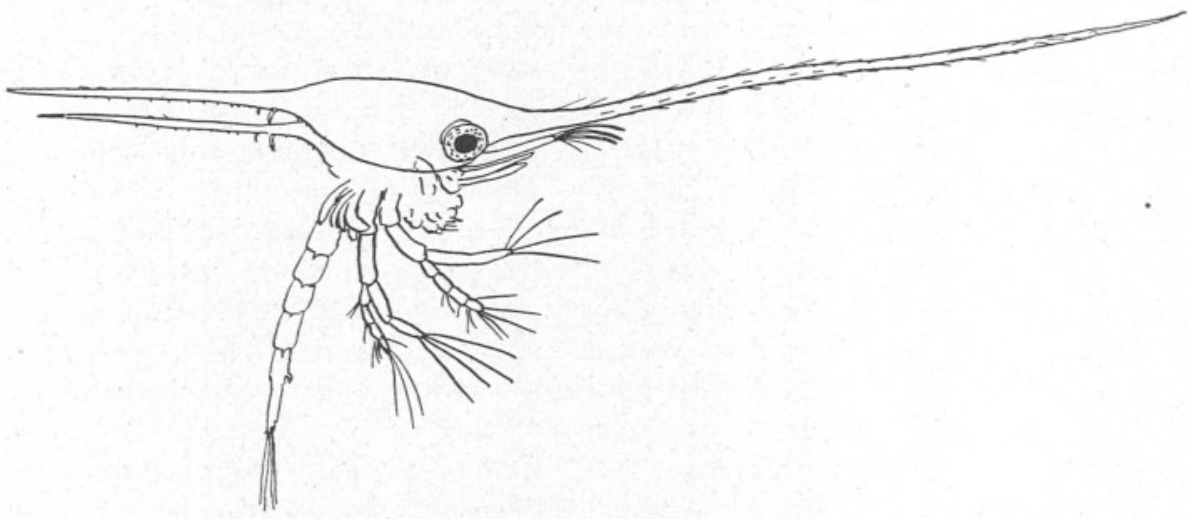

Fig. 5. Porcellana longicornis. Stage $\mathrm{I} b$, from plankton, $5.8 \mathrm{~mm}$. from spine to spine. 
Stage $I b$ (Fig. 5). This stage agrees exactly with Sars's first stage and is the commonest stage of I in the plankton. The length of a typical specimen is $5.84 \mathrm{~mm}$. from spine to spine, but the specimens may be longer or shorter. The rostrum is $3.3 \mathrm{~mm}$; the posterior carapace spines $1.5 \mathrm{~mm}$; the length of the body, without rostrum, $2 \cdot 2 \mathrm{~mm}$. The form is the same as I $a$ and the armature of the spines is the same, but the third maxillipede and legs are more developed. This stage from the plankton moulted into II $a$ many times in finger bowls. It has never been seen to moult into II $b$.

Stage IIa (Figs. 6, $7 a-f$ ). This stage is earlier than Sars's last stage, but of much the same form. It is frequently found in the plankton, and has moulted once from I $a$ and many times from $\mathrm{I} b$ and itself moults to II $b$. The large ventral spines on the posterior carapace spines have now disappeared and only a few short spines remain. It has all the characters of stage II. The pleopods are very small and occur on somites $2-4$. The telson has a sixth pair of long setae situated on the central prominence between the

Fig. 6. Porcellana longicornis. Stage II $a$ from I $b, 9 \cdot 3 \mathrm{~mm}$. from spine to spine.

two short hairs. There are II setae on the exopods of the first and second maxillipedes and 4 on the exopod of the third maxillipede. The length of the long spines is very variable. A specimen which moulted from I $a(4.5 \mathrm{~mm}$. from spine to spine) measured $7.5 \mathrm{~mm}$. from spine to spine. A typical specimen moulted from $\mathrm{I} b$ measured $8.8 \mathrm{~mm}$. from spine to spine, the rostrum measured $5.6 \mathrm{~mm}$., the posterior spines $2.5 \mathrm{~mm}$., the body $2.6 \mathrm{~mm}$. As a rule the posterior spines are about one-third the length of the rostrum, sometimes more, but never so much as half as they are in Porcellana platycheles. The legs are much more developed than they are in stage I, but still slender. Their lengths and the length of the pleopods are very variable. The endopod of the first leg shows signs of a chela, as also does the fifth leg which is hidden under the others. This stage moulted several times in finger bowls to stage II $b$. It is the stage figured by Gurney (I942, p. 256) as Porcellana sp.

Stage II $b$ (Fig. $7, g-l$ ). This is similar to Sars's last stage and may be taken to be its equivalent although the third maxillipede and legs are rather longer. It differs little from II $a$, but the pleopods are distinctly longer and the third maxillipede and legs more developed. The rostrum and posterior spines vary much in length. A specimen may measure $9 \mathrm{~mm}$. from spine to 


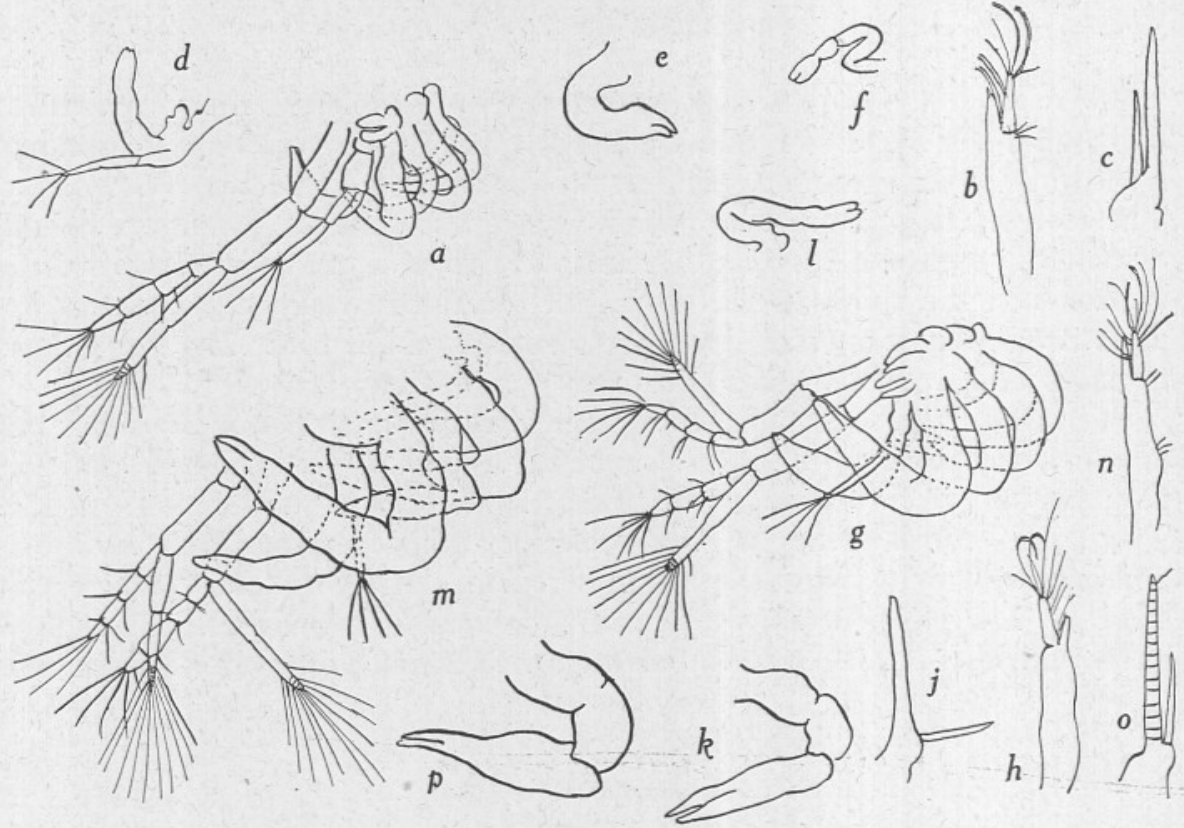

Fig. 7. Porcellana longicornis: $a$, stage II $a$, rather more developed than Fig. 6 from plankton; $b$, antennule; $c$, antenna; $d$, third maxillipede; $e$, first leg; $f$, fifth leg; $g$, stage II $b$; $h$, antennule; $j$, antenna; $k$, first leg; $l$, fifth leg; $m$, stage II $c$ or late $b ; n$, antennule; $o$, antenna; $p$, first leg.

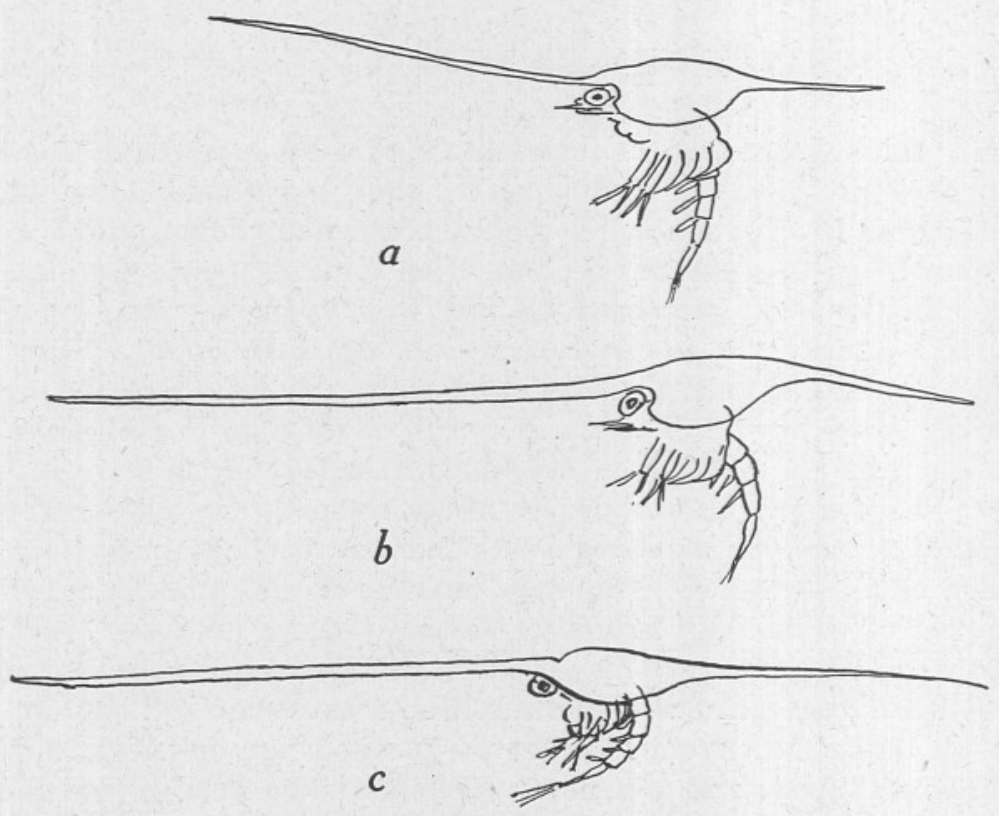

Fig. 8. $a, b$. Porcellana longicornis, last stage: $a$, with short spines; $b$, with long spines; c, Porcellana platycheles, last stage. 
spine, but II mm. is not uncommon (Fig. 8). In some specimens the posterior spines are nearly double the length they are in others. In one measuring $9 \mathrm{~mm}$. from spine to spine the rostrum is $5 \mathrm{~mm}$.; posterior spine $2.5 \mathrm{~mm}$.; body $3 \mathrm{~mm}$. in length. Thus it is only the body and appendages which are larger than II $a$. This stage moulted several times to the post-larva, but there is a more advanced stage frequently found in the plankton which is here called II $c$. It has not been reared from II $b$ nor has the post-larva been obtained from it. In lengths of spines and body it differs little from II $b$, but the third maxillipedes and legs are considerably larger (Fig. $7, m-p$ ) making the thoracic region very heavy. The pleopods are larger and longer and the antennal flagellum is conspicuously jointed under the cuticle. It is possible that this is an alternative stage to II $b$ or perhaps merely II $b$ grown much more than usual before moulting to the post-larva, or it may be that a moult has taken place because conditions were unsuitable for an early change to postlarva.

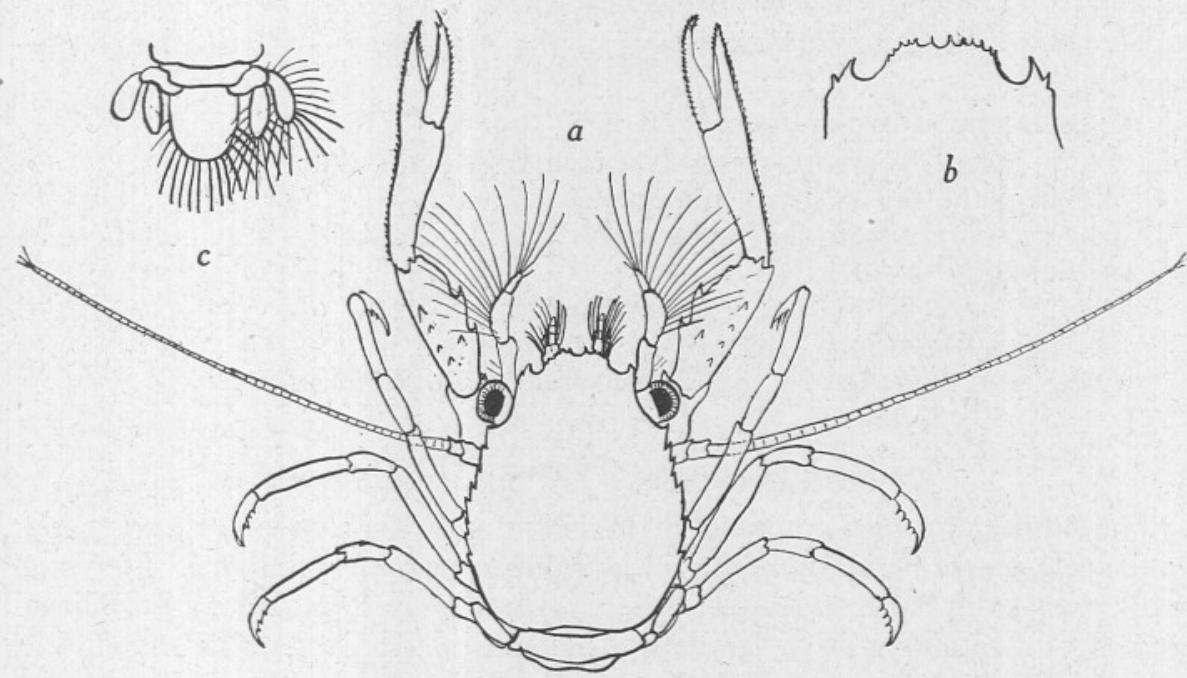

Fig. 9. Porcellana longicornis: $a$, post-larva from II $b$, carapace $\mathrm{I} \cdot 6 \mathrm{~mm}$. long; $b$, front of carapace; $c$, telson and uropods.

The Post-larva (Fig. $9 a, b, c$ ). This was obtained several times by moult from II $b$. It is clear and transparent with small red chromatophores scattered about the body, especially in the front of the carapace and on the legs. Most of the chromatophores appear yellow by reflected light except those in the abdominal region which remain red. The post-larva can be recognized as a Porcellana, but is not very like the adult. The carapace measures $\mathrm{I} .6 \mathrm{~mm}$. in length and $\mathrm{I} \cdot 3 \mathrm{~mm}$. in breadth. The front is 3 -lobed, the middle portion minutely toothed, whilst the lateral parts end in a strong tooth with small 
laterals. The sides of the carapace have strong teeth for nearly the whole length. The legs are functional, the chelae held out in front of the body when swimming, like a Galathea. The carpus of the chela is armed with 2 strong internal teeth, the propodus being fairly slender with hardly any hairs and bordered externally with small teeth. The dactyl has a similar armature. The dactyls of the remaining legs end in fairly strong claws and have 3 or 4 additional teeth. The sixth abdominal somite is now separated from the telson and bears setose uropods. There are 3 pairs of setose pleopods, on somites 2-4. The telson is not yet divided by sutures. It is rounded posteriorly and bordered by many setae. Although specimens lived for some time in bowls and plunger jars they all died before any moult was obtained.

The post-larval stage figured by Stebbing (I893) and attributed by him to this species is correctly identified, although Williamson (1915) regards it as probably belonging to Porcellana platycheles. Williamson has roughly described the larvae of $P$. longicornis and $P$. platycheles, but the details are insufficient to identify the two species accurately.

We thus have the following stages in the life history of Porcellana longicornis:

Egg hatches as a pre-zoea.

I $a$ by moult from pre-zoea, also, rarely, in plankton.

II $b$ in plankton only (not obtained by moult).

II $a$ by moult from I $a$ (once only) and I $b$ (usually), also common in plankton.

II $b$ by moult from II $a$, also common in plankton.

II $c$ in plankton only (not obtained by moult).

Post-larva from II $b$ by moult, also, rarely, in plankton.

\section{Porcellana platycheles (Pennant) (Figs. IO, II)}

The adults are very common in the Plymouth district under stones between tide-marks on all rocky shores and down to about 3 fathoms. Breeding takes place from April to August, rarely earlier or later. No larvae have been seen after September. The larvae are present in the late spring and in the summer plankton inside the Breakwater, very rarely outside. The eggs are brownish green, measuring when ready to hatch $0.48-0.52 \mathrm{~mm}$. in length and $0.42-0.45 \mathrm{~mm}$. in breadth. The egg hatches as a pre-zoea measuring $2.5 \mathrm{~mm}$. in length without the long spines. The rostral and posterior spines are folded in and much wrinkled (Fig. I). There is red and orange pigment on the rostrum and spines and red and orange chromatophores show beneath the cuticle on the thorax and red on the abdominal somites. The antennule has long feathered spines, two at the tip and one on the side, the aesthetes of the first larva protruding slightly but not covered by spines. The antenna has 5 long feathered spines on the exopod and one on the endopod. The third maxillipede and legs are further developed than they are even in stage I $a$ of $P$. longicornis. 
The First Larva (stage I $b$, Fig. Io $a$ ). The first larva which moulted from the pre-zoea is in a later stage than in P. longicornis, stage I $a$ being omitted. The rostral and posterior spines are very long and coloured red for nearly the whole length without bars. The red is, however, masked by a dull brown so that it rarely appears bright. The length from spine to spine in a typical specimen is $7.5-8 \mathrm{~mm}$. In some of $8 \mathrm{~mm}$. the rostrum measures $4.5 \mathrm{~mm}$; posterior spines $2.5 \mathrm{~mm}$; body $2.2 \mathrm{~mm}$. The posterior spines are always half or more the length of the rostrum. The animal is clear and colourless except for a faintish pink tinge in the thorax, patches of red on the thorax and at the base of the maxillipedes, on the sides of the abdominal somites and base
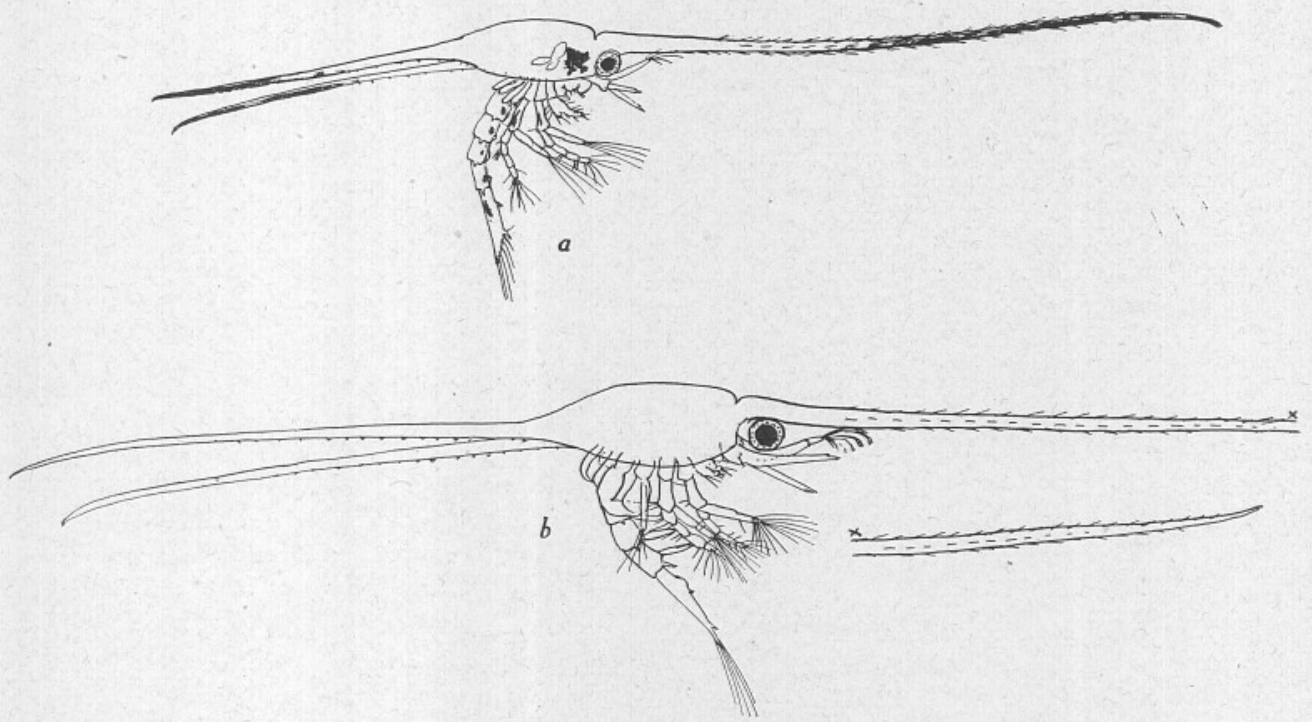

Fig. Io. Porcellana platycheles: $a$, stage $1 b$ from plankton, $8 \mathrm{~mm}$. from spine to spine; $b$, stage II $b$ from plankton, II $5 \mathrm{~mm}$. from spine to spine.

of telson. The rostrum curves upwards slightly and is covered with fine spines. The posterior spines reach a long way beyond the telson and have a few short spines, but no large spines such as distinguish the first stage of $P$. longicornis. The third telson spine (first long seta) has long fine spines, coarser however than on the main part, at its tip (Fig. 4a), in contrast to the hook-like spines of $P$. longicornis. Rudiments of the third maxillipede and legs are well advanced. This stage from the plankton moulted to the second stage similar to II $b$ of $P$. longicornis, II $a$ being omitted.

Stage $I I b$ (Fig. Io $b$ ) moulted from $\mathrm{I} b$, and was also obtained from the plankton. It is similar to II $b$ of $P$. longicornis, but is variable in size. There are 4 pairs of pleopods, on somites $2-5$, and these vary in length. In a specimen II. $5 \mathrm{~mm}$. in length from spine to spine the rostrum was $7 \mathrm{~mm}$.; posterior spine $4.2 \mathrm{~mm}$; body $3.5 \mathrm{~mm}$. The telson has the sixth long seta 
situated on the central prominence as in all the species of Porcellana. There are 12 setae + a very small one on the exopods of the first and second maxillipedes and 4 on the third. There is a trace of the chela on the first leg and on the fifth leg and the legs are not very well developed. A specimen belonging to this stage from the plankton moulted to the post-larva in July and another one a few days afterwards. A third and a fourth died whilst moulting. There is a later stage similar to stage II $c$ of $P$. longicornis in which the limbs are much more developed than in II $b$, but no moult was obtained from II $b$. One of these later stages died whilst moulting to the post-larva.
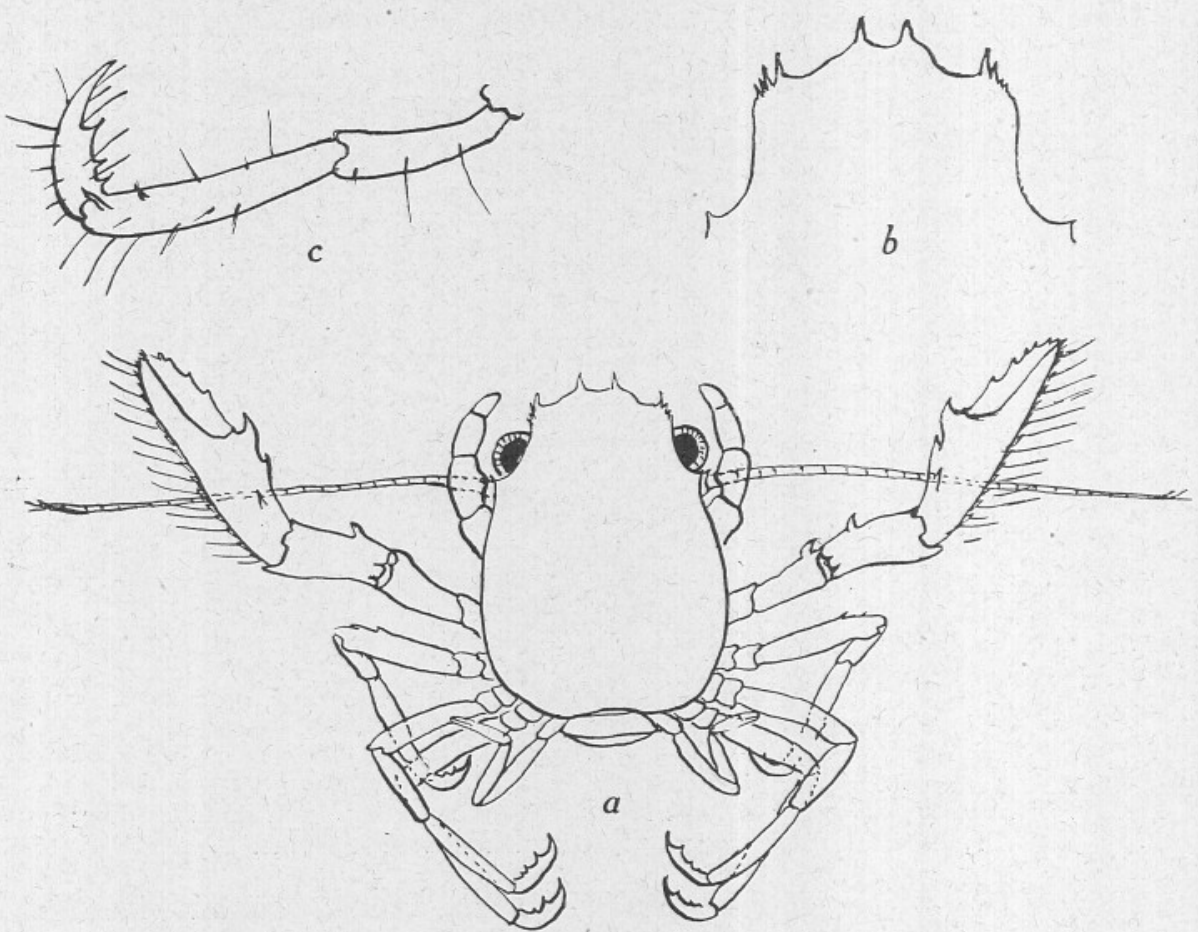

Fig. II. Porcellana platycheles: $a$, post-'arva from II $b, 9.6 \mathrm{~mm}$. across carapace; $b$, front of carapace; $c$, end of last leg.

The Post-larva (Fig. II). This was obtained by moult from II $b$ from the plankton. It is smaller than $P$. longicornis and the chelae are much more hairy and shorter. The telson is a simple plate. There are four pairs of setose pleopods and setose uropods. It is nearly colourless, but there are small scattered red chromatophores which become more conspicuous after the first day of moulting from the larva. No further stages were obtained. The carapace measured $\mathrm{r} .44 \mathrm{~mm}$. in length and $0.96 \mathrm{~mm}$. in breadth. The front although roughly three-lobed projects more in the centre than in $P$. longicornis and has only 2 teeth, the lateral part having 4 teeth, the front one the 
largest. The third maxillipedes and first legs are shorter and broader than in $P$. longicornis, the first leg with only one internal tooth on the carpus and the propodus thick and stout with a fringe of thick hairs externally besides fine teeth. The dactylus is armed with a few strong teeth. The chelae in the two species foreshadow the form of the adult and it is easy to distinguish between them. The dactyls of the remaining legs have 3 teeth internal to the terminal claw.

The stages in the life history of $P$. platycheles may be summed up as follows:

Egg hatches as a pre-zoea.

$\mathrm{I} b$ by moult from pre-zoea.

II $b$ from $\mathrm{I} b$ by moult.

II $c$ in plankton (not obtained by moult).

Post-larva from II $b$ and II $c$ by moult.

$P$. platycheles thus has fewer stages than $P$. longicornis, I $a$ and II $a$ being omitted.

We are now in a position to compare the two species and the following table shows the chief differences:

Number of larval
stages
Posterior spines
Third telson spine
Pleopods (stage II)
Armature of posterior
spines (stage I)
Rostrum

\section{P. longicornis}

3 essential ( 2 alternative, making 5 in all) I $a$, I $b$, II $a$, II $b$, II $c$ about $\frac{1}{3}$ rostrum, never $\frac{1}{2}$ with hooks at end 3 pairs on somites $2-4$

2 conspicuous spines ventrally near the origin red in wide bars

\section{$P$. platycheles}

2 essential ( $I$ alternative, making 3 in all) $\mathrm{I} b, \mathrm{II} b$, II $c$ about $\frac{1}{2}$ rostrum, never less with fine setae at end 4 pairs on somites $2-5$ these spines absent

red, masked with brown evenly, not in bars

\section{The LaRvae of the Genus Petrolisthes}

Petrolisthes armatus was hatched from the egg in Bermuda, but the late stages are as yet unknown. Gurney (I938a) describes an early and a late stage of a Porcellanid from the Red Sea which he attributes to this genus with a query. As from the reason he gives it is extremely likely that this is so, and the early larva agrees in essentials with that of $P$. armatus, we may assume that it really is a Petrolisthes. They differ from Porcellana in two points: (i) in the first larva the seventh seta of the telson (fifth long seta) arises from the central prominence, and (ii) (in the Red Sea form and, presumably, in Petrolisthes armatus) there is a central spine instead of an extra pair of setae in the late larva. The Red Sea form has 4 pairs of pleopods. The three larvae ascribed to Petrolisthes by Menon (I937) have all the characters of Porcellana, but, on the other hand, his Porcellanella larva agrees with Petrolisthes in essentials. 


\section{Petrolisthes armatus (Gibbes) (Fig. I2)}

This species was hatched from the egg as a pre-zoea which swam about for some hours before moulting to the first larva. It was unfortunately impossible to be sure of the characters of the pre-zoea as the cuticle was so extremely delicate that it was always damaged.

The First Stage ( $\mathrm{I} a$ ). The rostrum and posterior spines are colourless, but there are patches of red chromatophores in the mouth region, on the base of the second maxillipedes, on the sides of the abdominal somites and dorsally on the telson. The length from spine to spine is $9 \mathrm{~mm}$.; posterior spines I. $6 \mathrm{~mm}$.; rostrum $6 \mathrm{~mm}$.; body $2 \mathrm{~mm}$. The rostrum is covered with small

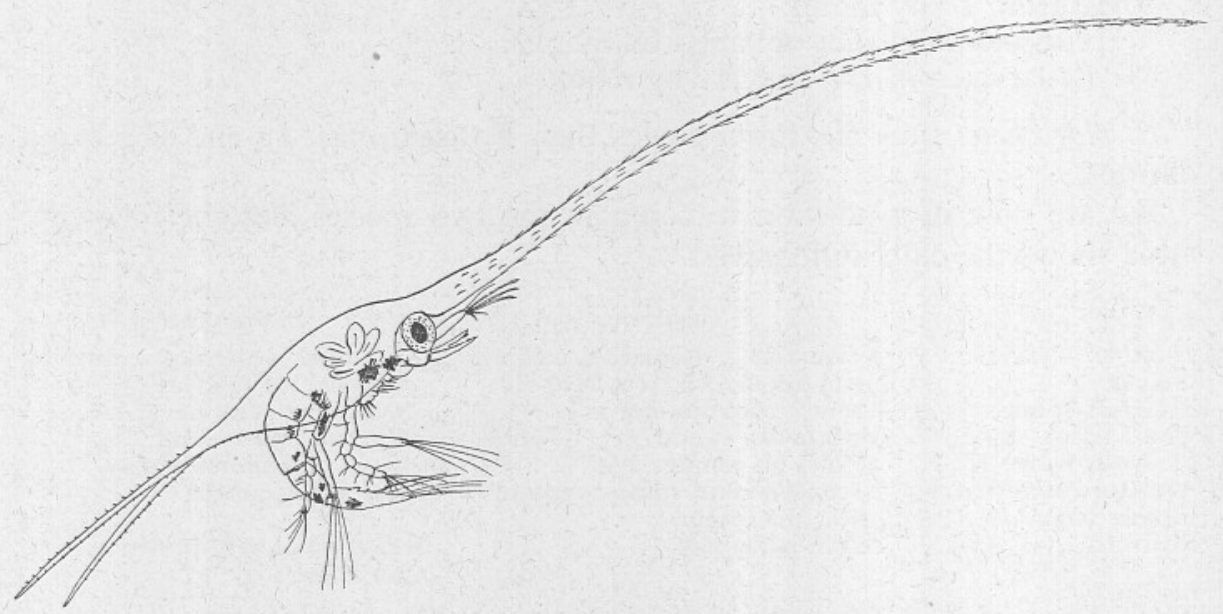

Fig. 12. Petrolisthes armatus from Bermuda. Stage I $a$ from pre-zoea from egg, $9 \mathrm{~mm}$. from spine to spine.

spines and minute protuberances. The posterior spines are covered with small spines which continue on to the posterior edge of the carapace. The telson is as broad as it is long. The appendages are very similar to those of Porcellana. The rudiments of the third maxillipedes and legs are exceedingly small. The long setae on the telson all have coarse spines at the tip, but the third seta (first long seta) has them larger and more numerous. No further stages of this species were obtained.

Gurney's (I938a) description of stage II of Petrolisthes sp. shows that it differs little from stage II of Porcellana except in the telson as noted above. The exopod of the third maxillipede has no setae. He regards the species as having only two stages.

Faxon (I879) describes a larva which he attributes to Polyonyx macrocheles which resembles Porcellana in its telson and has pleopods on somites 2-5, thus resembling $P$. platycheles. 
The known Porcellanid larvae thus fall into two groups divided by the form of telson:

A. Fifth long seta of telson situated outside the central prominence, a sixth seta on the prominence in stage II.

I. Pleopods on abdominal somites 2, 3 and 4

[Porcellana longicornis. Menon's Petrolisthes sp. I and 2, and his Porcellanid forms I and 2 (probably all Porcellana) (see Menon, 1937, 1940)]

II. Pleopods on abdominal somites 2, 3, 4 and 5

[Porcellana platycheles, $P$. inaequalis, Menon's Porcellanid, form 3 (=P. serratifrons?), Faxon's Polyonyx macrocheles]

B. Fifth long seta of telson on the central prominence, in late stages, no sixth seta, but a central tooth present

Pleopods on abdominal somites 2, 3, 4 and 5 (so far as is known) [Petrolisthes armatus, only first larva known, so number of pleopods not ascertained, Gurney's Petrolisthes (?) sp., Menon's Porcellanella (probably Petrolisthes)]

\section{LITERATURE}

The references to the larvae will be found in Gurney's (1939) Bibliography of the Larvae of Decapod Crustacea, Ray Society, and (1942) The Larvae of Decapod Crustacea, Ray Society.

The following work is not included in the above:

Nicol, E. A. T., I932. The feeding habits of the Galatheidae. Fourn. Mar. Biol. Assoc., Vol. xviII, pp. 87-I06. 